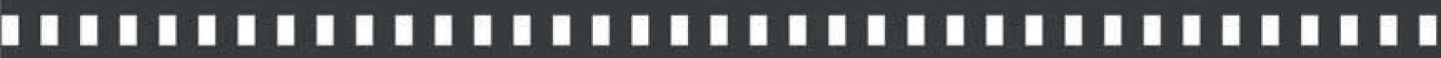

\author{
Entrevista: Gabriel Uchida, por \\ uma fotografia sincera e engajada
}

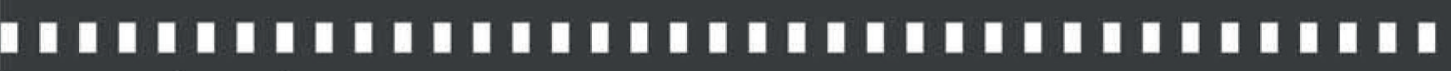

Marcia Boroski 


\title{
Gabriel Uchida: por uma fotografia sincera e engajada
}

\author{
Marcia Boroski*
}

Até 2009, Gabriel não teve contato com a fotografia. Ela surgiu "meio que por acaso", como ele mesmo diz, um ano após se formar em Comunicação Social - Jornalismo pela Universidade Católica de Santos. Segundo ele, a parte técnica do acaso é fruto do acúmulo de referências da arte contemporânea e do cinema. $\mathrm{O}$ posicionamento social-político, evidente na sua produção, vem de um incomodo com o modo de representação de alguns movimentos e grupos sociais, como a Marcha das Mulheres e as torcidas organizadas, na imprensa brasileira. Aos 29 anos, Gabriel Yoshio Fleming Uchida, que nasceu no interior do Estado de São Paulo, já soma seis anos de dedicação à fotografia independente.

Foi no primeiro ano como fotógrafo que Gabriel iniciou o FotoTorcida, projeto pelo qual é amplamente conhecido e que lhe rende visibilidade internacional. Com esta iniciativa, retrata as grandes torcidas pela perspectiva de dentro: da arquibancada, e do ônibus, a caminho do estádio.

A cada novo projeto fotográfico, Uchida busca uma nova abordagem jornalística com relevância internacional. Alcançaas por esforçar-se em estar em relação sincera com o ambiente inserido, seja na Namíbia, nos EUA, na Etiópia, em Cuba, na Argentina, no Uruguai ou no Curdistão. Para tanto, o fotógrafo, que também cobriu as manifestações de junho de 2013, desenvolveu recentemente uma estratégia singular: reside em um país diferente a cada três meses. Cada mudança é muito bem pensada e a pauta, pesquisada e capitalizada. Hoje, também é fotógrafo da sucursal brasileira da Revista Vice e membro do coletivo jornalístico Ponte. Em entrevista exclusiva para a Discursos Fotográficos ${ }^{1}$, Gabriel Uchida comenta seu posicionamento político e estético com

\footnotetext{
* Jornalista e mestre em Comunicação pela Universidade Estadual de Londrina $1 \quad$ Entrevista concedida em outubro de 2015.
} 
relação à fotografia, os desafios da área no mercado brasileiro e seus próximos projetos.

\section{Primeiramente, como você vê a consolidação da fotografia digital e das plataformas digitais? Há alguma especificidade para o mobile?}

Se num primeiro momento o digital trouxe para a fotografia uma considerável mudança no rendimento e autonomia do processo - no sentido de economizar o tempo de troca de filmes, o custo do material e da revelação, e a maior capacidade de armazenamento dos cartões -, esta nova fase, com intermináveis inovações, tanto nas câmeras quanto no processo de pós-produção, é como uma explosão que cria um novo mundo. E é importante ressaltar que neste sistema atual estão todos os diversos tipos de câmeras, sejam as compactas, as de celulares ou as acopladas em drones. É, sem dúvida, um momento excitante para a fotografia, porque temos um horizonte em expansão diariamente. De maneira prática e simples, as câmeras de hoje "enxergam" muito mais do que as de antigamente. Mas, além disso, é fascinante notar que uma foto hoje pode conter muito mais informação, seja o nome do autor no arquivo, coordenadas de localização etc. Ou seja, com as novas tecnologias podemos muito mais criar uma imagem do que simplesmente registrar um fragmento de tempo - que também já é algo poderoso. Assim, a câmera fotográfica é uma arma muito mais potente hoje. Além disso, as plataformas digitais são outro avanço - a informação deixou de andar e passou a voar. Partindo dos pressupostos de que uma foto pode ser lida mais rapidamente do que um texto, e que velocidade e agilidade são objetos de desejo da comunicação contemporânea, é fácil entender a presença maciça e poderosa da fotografia nas plataformas digitais. Em todas as pesquisas recentes sobre redes sociais, que são o norte do fluxo de informação atual, a imagem é o tipo vencedor de informação mais compartilhada e consumida. E a cada dia menos importa o tipo de 
aparelho utilizado (celular, tablet, computador etc), pois as funções desempenhadas pelos dispositivos são praticamente as mesmas.

\section{Este seria o espaço para a fotografia de documentação hiperlocal?}

Acredito que as plataformas estejam todas interligadas e a mesma formatação de informação pode funcionar bem em diversas plataformas. É lógico que existe uma linguagem para o rádio e outra para a televisão, por exemplo, mas hoje a internet e a mobilidade criam uma rede em que está tudo ligado e acessível, e funciona. Nesse sentido, o que não é mais plataforma digital? Tudo está interligado, todo tipo de informação já virou um link. Desta forma, é sim fascinante pensar que a documentação hiperlocal, antes limitada à comunidade, pode alcançar através das plataformas digitais um campo global, ainda que seu conteúdo seja sobre uma questão pontual geograficamente.

\section{Como o mercado de trabalho brasileiro está absorvendo os fotógrafos?}

Mesmo quando desenvolvi trabalhos no Brasil, sempre foquei mais o mercado exterior, por questões financeiras e também por conta de um plano de trabalho. Mas o maior problema que vejo é no fotojornalismo brasileiro. A profissão não é valorizada pelos contratantes no sentido de que chegam a pagar míseros $\mathrm{R} \$$ 3 ou menos em uma foto. Imagina a situação de um fotógrafo que trabalha para uma agência e vai cobrir um jogo de futebol. Para esse tipo de pauta, geralmente é usada uma lente grande e cara, provavelmente o profissional vai ter o valor de um carro em equipamentos - e isso não é exagero. Por essa foto as agências pagam valores ridículos, algo entre R $\$ 2$ e R\$10. É uma situação insana. Certa vez eu fui a única pessoa da imprensa a presenciar e registrar um fato - torcedores do Palmeiras plantando cruzes com 
os nomes dos jogadores em frente ao estádio. Era notícia no país todo, mas só eu tinha as fotos. Dezenas de veículos vieram atrás de mim para comprar a foto, mas como era um furo e exclusiva disse que cada imagem valeria $\mathrm{R} \$ 300$. Chamaram-me de louco e apenas um veículo comprou a foto. Minha atitude foi uma declaração, um manifesto. E, além disso, antes de qualquer empresa, tenho de valorizar meu próprio trabalho.

\section{E os freelancers?}

Infelizmente, a desvalorização do fotojornalista brasileiro é geral, seja para o contratado, seja para o freelancer.

\section{No cenário de crise no modelo de negócio do jornalismo, como a fotografia se (re)configura?}

Tudo bem que o empresário deve sofrer menos que o empregado, mas neste contexto eu tendo a ser otimista e pensar que é uma ótima oportunidade para mais trabalhos autorais, independentes, coletivos de fotógrafos, financiamento coletivo etc. Existem vários caminhos possíveis. Há crise, mas também sempre há espaço para ideias e trabalhos bons e relevantes.

\section{Ainda sobre este cenário, o financiamento coletivo parece ser uma boa saída. Consegue citar exemplos brasileiros?}

Gosto do financiamento coletivo, porque é uma alternativa que funciona para qualquer um que produza conteúdo (seja jornalista, fotógrafo, escritor etc) e é baseada em solidariedade e independência, além de ser mais simples e prático do que editais, patrocínios e publicidade. Os Jornalistas Livres arrecadaram R\$ 130 mil para iniciar o projeto, o fotógrafo Jorge Bispo arrecadou mais de R\$ 38 mil, que bancaram a publicação do seu livro, são vários os exemplos. 


\section{Agora sobre a Revista Vice: qual a representação do veículo no cenário brasileiro?}

É simples explicar porque eu gosto da Vice: quando abro o site de algum outro jornal brasileiro, tenho de procurar alguma coisa para ler, ou seja, geralmente a maioria do que tem ali não me é atraente, só ler o título meio que já serve. Na Vice é o contrário, tenho vontade de ler todo o conteúdo. Isso acontece porque é uma pauta diferente, uma abordagem diferente, foge do padrão clichê tradicional e, além de tudo, é um conteúdo de qualidade. A revista Piauí é outro exemplo de excelente material. No caso específico da Vice, acho que é uma alternativa de jornalismo com uma cara mais jovem, no sentido de ser novo e contemporâneo, não juvenil - que é o que me parece quando outros jornais tentam alcançar a juventude, mas só produzindo memes de internet.

\section{Como foi sua experiência cobrindo as manifestações de junho de 2013? Onde publicou o material?}

Fotografei pouco as manifestações de 2013, porque estava muito envolvido em outros projetos de futebol para a Copa do Mundo, mas algumas fotos minhas saíram em uma revista na Alemanha.

Mesmo muito social e política, sua fotografia é artística, certo? De onde vêm suas referências?

O que eu vejo de mais livre e transgressor é a arte, por isso é o meu norte. Antes de começar a fotografar já me interessava por gente como Hélio Oiticica e Cildo Meireles. Mas acho que grande parte da minha formação foram escritores e poetas mais marginais e "sujos", gente como Hunter Thompson, Roberto Piva, Lourenço Mutarelli, Glauco Mattoso, Henry Miller, Baudelaire, Bukowski... 
Então, como exatamente a fotografia entrou na sua vida? Há quanto tempo?

Entrou tarde, mais ou menos em 2009. Sempre me interessei por arte e principalmente por cinema - acho que daí veio a fotografia. A primeira vez que saí para fotografar foi num 8 de março, na Marcha Mundial das Mulheres em São Paulo. Logo depois já comecei o FotoTorcida.

Você é mundialmente conhecido pelo projeto FotoTorcida. Como e quando começou? Mais alguém está tocando o projeto com você?

Começou em 2009, meio que por acaso. Fui acompanhar uns amigos em um jogo entre Portuguesa e Santo André e acabei fazendo as fotos. Como estava ali mais pelo "passeio", acabei fazendo fotos dos meus amigos e dos torcedores ao redor. Disso surgiu a ideia do projeto. Uma ou outra vez já tive alguns amigos muito próximos me ajudando, mas geralmente era só eu mesmo e agora, infelizmente, o projeto está um pouco parado porque estou esperando o livro e focando em outros trabalhos.

\section{Como será este livro?}

Ele está sendo produzido na Alemanha, com o conteúdo do FotoTorcida. O nome é On The Terraces - The Real Brazilian Football e sairá pela BlickfangUltra.

\section{Quais torcidas de quais países já fotografou? Consegue citar algumas particularidades das torcidas?}

Fotografando futebol foram Argentina, Uruguai, Cuba, Estados Unidos, Namíbia, Etiópia e Alemanha. Nós, latinos, somos 
mais quentes, caóticos, emocionados. Os europeus, no geral, são mais organizados e sérios. Nos Estados Unidos, essa cultura ainda está muito no começo e estão buscando referências tanto da Europa quanto da América Latina, então é meio que uma mistura.

\section{E qual o papel político do FotoTorcida?}

Mostrar que o povo é tão importante quanto o jogador famoso, mostrar que somos todos iguais. Mas, além disso, estudar e dar voz a um grupo oprimido e demonizado, que são as torcidas organizadas. Se ninguém questiona ou investiga, a opinião pública vai seguir sempre a mesma linha de pensamento do poder, dos grandes empresários e políticos. É como se fosse a história contada pelo "vencedor". Ou seja, os movimentos sociais, as comunidades indígenas, os moradores de periferia, as torcidas organizadas vão ser sempre os errados da história.

Consegue sintetizar o tipo de relação que estabelece com as torcidas?

Minha relação com as torcidas é de extrema confiança. Eu sei bem o que acontece nesse mundo e eles entendem bem qual é o meu trabalho.

Tamanha a perversidade como são tratados pela imprensa, os movimentos sociais podem mostrar-se não muito favoráveis à presença da mídia. Quais estratégias você usa?

Sinceridade e muita conversa. Não estar atrelado a nenhum grande veículo também acaba ajudando bastante, porque na rua um funcionário, às vezes, acaba tendo de responder por todo um jornal, por exemplo.

Sobre sua participação na Ponte jornalismo, como entrou para 


\section{o coletivo? Lá faz audiovisual e fotos?}

Antes de surgir a Ponte, eu e mais dois grandes amigos, o André Caramante e o Guilherme Kastner, já estávamos nos reunindo com a ideia de fazer algo parecido. Então, o Caramante foi chamado por outro grupo que estava com o mesmo pensamento, por isso, foi natural que nos juntássemos. Mas eu, infelizmente, nunca colaborei tanto com a Ponte, porque sempre estive muito envolvido em outros projetos. Com eles atuei mais em vídeo, por exemplo, em edição e filmagem em entrevistas com gente como Criolo e Emicida. Um dos trabalhos mais marcantes foi quando fizemos um vídeo sobre um menor de idade que estava injustamente preso e, inclusive, mostrávamos que o garoto estava em casa durante o crime. Após a reportagem, o menino foi solto. Esse tipo de trabalho vale mais do que qualquer contrato internacional e fico triste em não poder colaborar mais. Por outro lado, estou também tranquilo em saber que tem gente de peso, como André Caramante e Bruno Paes Manso, tocando o projeto.

\section{Você viaja bastante e já fotografou diversos países. Poderia citar alguns deles e que tipo de trabalho desenvolveu?}

Já estive em mais de dez países, geralmente fotografando. Já fotografei futebol na Argentina e no Uruguai; na Etiópia fiz um ensaio sobre futebol e outro de rua; na Namíbia fotografei a tribo Himba jogando bola; em Cuba fiz mais de uma dezena de trabalhos; na Alemanha fotografei futebol e manifestação política; na Turquia fotografei as eleições e um comício em Diyarbakir, que é considerada a capital dos curdos; nos Estados Unidos fotografei futebol e um outro projeto mais artístico.

\section{Estas viagens são sempre feitas pensando em trabalhos fotográficos?}

É uma mistura, eu penso que não tenho pátria nem patrão, 
então meu modelo hoje é viver por dois ou três meses em cada país e usar esse tempo para desenvolver trabalhos. Meu processo é um pouco diferente de uma rotina de trabalho mais normal. Primeiro que eu aboli a diferenciação dos dias, achava muito injusto "perder" cinco dias e curtir dois na semana. Se você parar e pensar, é uma proporção injusta e cruel! Então, a organização dos dias responde mais a um fluxo natural do que tem de ser feito mesmo, contando sempre que o ócio é criativo, e criatividade é um ponto importantíssimo no meu processo. Recentemente, passei um mês isolado em uma fazenda nos Estados Unidos, minhas únicas atividades eram cuidar do que plantávamos para comer, fazer trilhas, nadar no lago e ler. Neste tempo eu não fotografei, mas pensei em diversos projetos e estudei dezenas de assuntos. Era trabalho ou férias? Na verdade, um híbrido que busca muito mais atender às minhas necessidades ou anseios do que funcionar dentro de uma linha de produção da máquina capitalista.

\section{O ensaio "Nova Palestina" parece ter uma singularidade específica. Ele não convoca os tradicionais elementos emocionantes da fotografia em preto e branco de mazelas sociais. $O$ ensaio sensibiliza por apresentar uma realidade próxima e construída pelo homem. É isso mesmo?}

É isso. Este ensaio foi construído de maneira a expor e documentar mais uma realidade, ao invés de simplesmente emocionar por um caminho mais direto e claro. Eu poderia, por exemplo, fazer retratos mais fechados de crianças com fisionomias sofridas. Não descarto esse tipo de fotografia, mas a ideia aqui era muito mais estudar como aquelas pessoas construíram sua resistência e o modo de vida ali naquele terreno, antes abandonado, de modo a construir um retrato da situação da ocupação. Mas se a pessoa lê as fotos e pensa naquele cenário todo, não deixa de ser algo comovente. 


\section{Como teve a ideia deste ensaio e em quanto tempo fez a produção?}

Foi um trabalho curiosamente rápido, cerca de uma semana de pesquisa e produção e um dia de fotos. A ideia veio de uma simples curiosidade, quase necessidade, de conhecer aquela situação. No geral, o meu trabalho segue uma linha de temas de violência e marginalidade - neste caso, que estavam vivendo à margem da sociedade. Pessoalmente, essa pesquisa não precisava necessariamente resultar em um ensaio, era muito mais uma questão de conhecer aquela história de perto. Além disso, enxergava uma relação muito forte dessa ocupação com as torcidas organizadas. Então, quis levar a pauta das ocupações para esse outro mundo, o das torcidas, por acreditar que movimentos sociais e grupos marginalizados deveriam, pelo menos, se conhecer.

\section{O que você tem sonho de fotografar?}

De cara, poderia lhe responder que seria fotografar, muito em breve, o velório de um certo Governador, mas aí eu me lembro que vários outros também poderiam entrar na lista e que tantas outras figuras políticas são detestáveis. Eu nunca estou contente com meu trabalho, quero sempre mais no próximo. Desde criança sonho em registrar/vivenciar o Exército Zapatista de Libertação Nacional, no México, mas obviamente depois deles viriam outros sonhos e vontades. 